Dermatology 2012;224:307-308

DOI: $10.1159 / 000339477$

\section{Facial Hidradenitis Suppurativa in a 28-Year-Old Male Responding to Finasteride}

\section{Doménech, J. Matarredona, J.C. Escribano-Stablé, J.P. Devesa, J. Vicente, A. Jaén}

Dermatology Department, Elx/Elche General University Hospital, Elche, Spain

\section{Key Words}

Hidradenitis suppurativa $\cdot$ Facial hidradenitis suppurativa $\cdot$ Acne inversa $\cdot$ Acne $\cdot$ Acne conglobata $\cdot$ Finasteride

We read with interest a paper published in a recent issue of Dermatology in which Poli et al. [1] describe for the first time how hidradenitis suppurativa (HS) can affect the face and back. These patients referred to suffer from typical hidradenitis, with skin lesions on their face or back, which are not present in the case of acne: rope-like or bridged scars, hypertrophic or raised plaques with multiple carbuncle-like openings, 'worm-eaten scars' and coalescent nodules with round ulcerations.

In written sources, HS has been associated with several risk factors. Although no causal association has been established with tobacco addiction, it has been deduced in some studies that approximately $90 \%$ of the patients who present HS lesions are smokers, tobacco being the triggering/aggravating factor of the initial lesions [2]. This fact has led to some authors suggesting that the first lesions of the illness be redefined as a separate entity: smoker's boils [2]. At the same time, this supports a new hypothesis on the pathogenesis of HS [3].

On the other hand, obesity and overweight are the only risk factors contrasted in the studies carried out until now [4].

Finally, in male patients, studies carried out on sex hormone levels or hyperandrogenism have not provided any conclusive results as far as their relationship with HS is concerned [5]. However, it is known that some medicines which interact at the same level as some sex hormones have had satisfactory results on HS $[4,5]$.

In some patients with HS, there is a concomitant presence of acne conglobata. These two diseases, when associated with perifolliculitis capitis abscedens et suffodiens, also known as dissecting cellulitis or dissecting folliculitis, are usually referred to as the follicular occlusion triad, and as a tetrad when pilonidal cysts are also added $[4,5]$.

There are different therapeutic options for the treatment of HS, no medicine being considered to be the first-line treatment. Both oral and topical antibiotherapies have been tested, as well as combinations of different antibiotics [6], generally obtaining pos- itive results with varying levels of improvement. Isotretinoin, etretinate and acitretin $[4,5,7]$ used individually have provided positive results, but the results tend to be limited. Colchicine seems to be ineffective [8] on HS. Tumor necrosis factor- $\alpha$ inhibitors such as infliximab, etanercept or adalimumab seem to provide disparate results on HS, according to different studies $[4,5$, $9,10]$. The use of immunosuppressants like systemic corticosteroids and ciclosporin has given satisfactory results. In contrast, dapsone and methotrexate do not seem to be as effective $[4,11]$.

Finally, finasteride, a competitive $5 \alpha$-reductase inhibitor of type II, has proven effective in the treatment of HS lesions in some patients $[12,13]$. This drug reduces the plasma levels of the androgen $5 \alpha$-dihydrotestosterone, a hormone which has direct implications for androgenetic alopecia and benign prostatic hyperplasia. Although side effects are not very common with $5 \mathrm{mg} /$ day of finasteride, patients may show sexual impotence, a decrease in libido and a low ejaculatory volume [14]. Given that the said dose is normally used on patients over 40 years of age with a prostate pathology, there is no data on adverse effects when administered to younger patients.

The mechanism of action of the drug on the pathophysiology of the illness has yet to be clarified.

We report a 28 -year-old-male patient, nonsmoker, with a normal body mass index, who has been undergoing treatment in our clinic for several years, initially presenting several hidradenitis lesions in the groin area and axillae, a pilonidal cyst and severe facial damage with deep and painful nodules on his face, whereby some of them had self-limiting inflammatory outbreaks. These lesions resulted in abscessing and casual external drainage leaving scars with a worm-eaten appearance and hypertrophic ropelike bridged scars after healing. After being diagnosed with hidradenitis and acne conglobata, the patient was administered doxycycline, isotretinoin and several cycles of clindamycin and rifampicin, reporting a partial response to the joint treatment of clindamycin and rifampicin. Subsequently, the facial lesions worsened (fig. 1) with the appearance of inflammatory nodules on the scalp, back, chest and forearms, as well as severe damage to the axillae and groin. This led us to treat him with 3 doses of infliximab, $300 \mathrm{mg}$ every 6 weeks, with no response, which was eventually changed for etanercept, $50 \mathrm{mg}$ subcutaneously, weekly for 5 months, with no clinical improvement and even resulting in a progression of his skin lesions. The treatment with dapsone, $100 \mathrm{mg} /$ day, far from producing any benefit, resulted in a deterioration of the cutaneous disease. He was eventually treated with finasteride, $5 \mathrm{mg} / \mathrm{day}$, showing a significant improvement in the process. After a year under finasteride treatment, the patient's condition showed an almost complete remission of the cutaneous disease, without the appearance of new lesions (fig. 2). Analytical tests, including a hemogram, biochemical testing, follicle-stimulating hormone, luteinizing hormone, testosterone, prolactin and dihydroepiandrosterone sulfate levels, as well as a spermiogram

\section{KARGER}

Fax +41613061234

E-Mail karger@karger.ch

www.karger.com
C 2012 S. Karger AG, Basel

$1018-8665 / 12 / 2244-0307 \$ 38.00 / 0$

Accessible online at:

www.karger.com/drm
Carles Doménech Pérez

Av. Diputació, 13

ES-03810 Benilloba, Alicante (Spain)

Tel. +34620320991

E-Mail carles.domenech.perez@gmail.com 


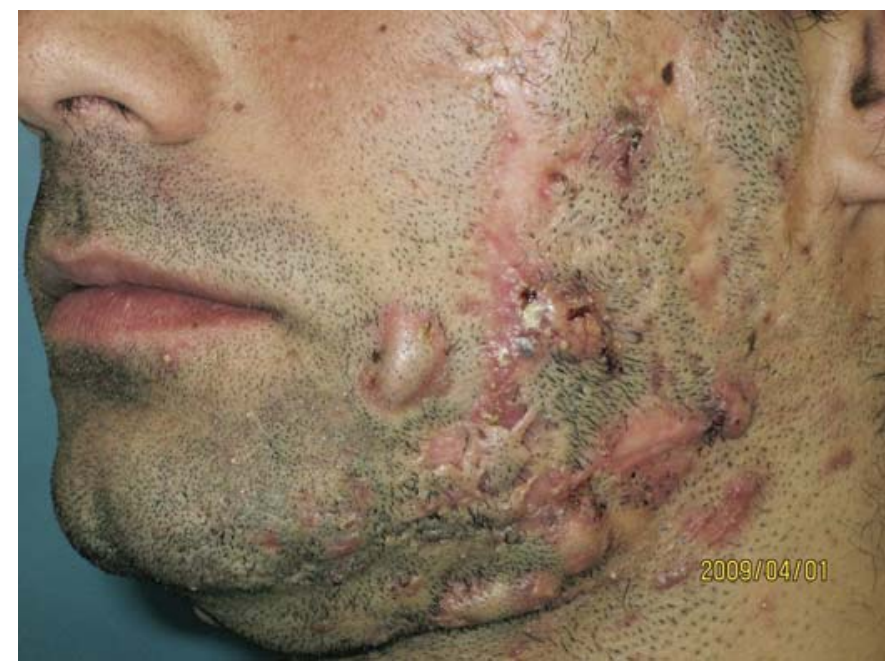

Fig. 1. Bridged scars and raised plaques with nodules: facial HS in active inflammatory process.

proved normal. Moreover, to date, the patient has shown no side effects related to taking finasteride.

Our patient has clinical characteristics similar to some cases described by Poli et al. [1]. We report a case of a patient with significant facial injuries caused by HS that also shows lesions in the groin area, axillae and scalp. In this report it should be noted that the patient's condition improved with finasteride, as described in some previous cases $[12,13]$.

It is important to be aware that this devastating disease can be located on the face and must be distinguished from acne conglobata, since both illnesses have a different prognosis and treatment, and otherwise may result in severe scarring of the face.

\section{Disclosure Statement}

The authors declare no conflict of interest.

\section{References}

1 Poli F, Wolkenstein P, Revuz J: Back and face involvement in hidradenitis suppurativa. Dermatology 2010;221:137-141.

2 Happle R, Köning A: Smoker's boils. Dermatology 2011;222:282-284.

3 Jemec GBE: The concept of 'smoker's boils' is suggestive of a new hypothesis on the pathogenesis of hidradenitis suppurativa. Dermatology 2011;222:196-197.

4 Revuz J: Hidradenitis suppurativa. J Eur Acad Dermatol Venereol 2009; 23:985-998.

5 Alikan A, Lynch PJ, Eisen DB: Hidradenitis suppurativa: a comprensive review. J Am Acad Dermatol 2009;60:539-561.

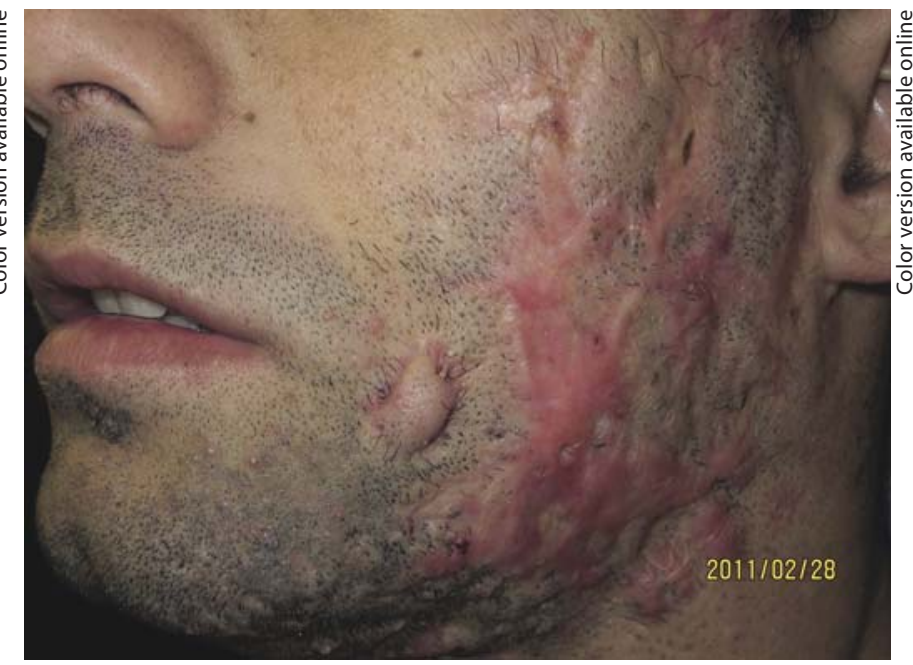

Fig. 2. After approximately 1 year of treatment with finasteride: notable remission of inflammatory activity.

6 Join-Lambert O, Coignard H, Jais JP, Guet-Revillet H, Poirée S, Fraitag S, Jullien V, Ribadeau-Dumas F, Thèze J, Le Gern AS, Behellil S, Leflèche A, Berche P, Consigny PH, Lortholary O, Nassif X, Nassif A: Efficacy of rifampim-moxifloxacin-metronidazole combination therapy in hidradenitis suppurativa. Dermatology 2011;222:49-58.

7 Scheman AJ: Nodulocystic acne and hidradenitis suppurativa treated with acitretin: a case report. Cutis 2002;69:287-288.

$\checkmark 8$ Van der Zee HH, Prens EP: The anti-inflammatory drug colchicine lacks efficacy in hidradenitis suppurativa. Dermatology 2011;223:169173.

9 Miller I, Lynggaard CD, Lophaven S, Zachariae C, Dufour DN, Jemec GB: A double-blind placebo-controlled randomized trial of adalilumab in the treatment of hidradenitis suppurativa. Br J Dermayol 2011;165: 391-398.

10 Grant A, Gonzalez T Montgomery MO, Cardenas V, Kerdel FA: Infliximab theraphy for patients with moderate to severe hidradenitis suppurativa: a randomized, double-blind, placebo controlled crossover trial. J Am Acad Dermatol 2010;62:205-217.

-11 Yazdanyar S, Boer J, Ingvarsson G, Szepietowski JC, Jemec GBE: Dapsone therapy for hidradenitis suppurativa: a series of 24 patients. Dermatology 2011;222:342-346.

12 Joseph MA, Jayaseelan E, Ganapathi B, Stephen J: Hidradrenitis suppurativa treated with finasteride. J Dermatolog Treat 2005;16:75-78.

13 Farrell AM, Randall VA, Vafaee T, Dawber RPR: Finasteride as a therapy for hidradenitis suppurativa. Br J Dermatol 1999;141:1136-1153.

14 Vaughan D, Imperato-McGinely J, McConnell J, Matsumoto AM, Bracken B, Roy J, Sullivan M, Pappas F, Cook T, Dauricio C, Meehan A, Stoner E, Waldstreicher J: Long-term (7- to 8-year) experience with finasteride in men with benign hyperplasia. Urology 2002;60:10401044. 